\title{
EL PARTIDO FRENTE GRANDE, ANÁLISIS DE UNA EXPERIENCIA INCONCLUSA*
}

\author{
Juan Manuel Abal Medina*
}

\section{INTRODUCCIÓN}

La intención de este breve trabajo es comenzar a responder las preguntas que se relacionan con las características que adoptan los partidos políticos en el fin de siglo. Partiendo del supuesto de que en los últimos años se ha operado una radical transformación en los modelos organizativos de los grandes partidos políticos (Katz y Mair, 1997:103), tiene un gran interés el preguntarnos qué ocurre con los partidos políticos relevantes que han surgido en los últimos años.

Especialmente interesante resulta el entender qué formas organizativas adoptan las nuevas organizaciones frente a un entorno político caracterizado por la desconfianza creciente en lo político (Cavarozzi, 1996) y, en consecuencia, por la disminución de los incentivos a la participación partidaria (Ware, 1996:378). Como modelo interpretativo podemos sostener la existencia de dos posibilidades polares: que los nuevos partidos intenten reproducir el formato organizativo del modelo burocrático de masas, o que, por el contrario, adopten características que los acerquen al modelo de agencia electoral, es decir, una organización que haya perdido toda identidad organizativa y sea poco más que una etiqueta bajo la cual actúan empresarios políticos independientes. Entre ambos extremos existe el modelo llamado profesional electoral, que hasta ahora ha sido interpretado solamente como la transformación evolutiva de los partidos burocráticos de masas ya existentes (Panebianco, 1990: 487-512).

El trabajo analiza el proceso político de construcción y desarrollo de una de las nuevas organizaciones partidarias, el argentino Frente Grande, partido que ha transformado en los últimos años el tradicional formato bipartidista del sistema de partidos argentino (Abal Medina, 1995 y 1998a). Para ello realizaremos primero un recuento histórico de la breve experiencia de esta organización, desde sus orígenes al interior del Partido Justicialista ("peronista") hasta su actual situación como parte de la alianza electoral (la "Alianza") que las encuestas señalan como probable ganadora de las elecciones presidenciales argentinas de 1999. Tras esto trataremos de señalar las particularidades que este partido presenta a la luz de los conceptos tradicionales del estudio de los partidos políticos.

\section{PREHISTORIA ORGANIZATIVA: LOS PERONIS- TAS Y LA “TRAICIÓN" DE MENEM}

Desde sus inicios en el gobierno en 1989 el justicialista Carlos Menem comienza a implementar una serie de políticas que son visualizadas por algunos peronistas, y por muchos antiperonistas, como la antítesis del proyecto histórico del movimiento creado por Juan Domingo Perón '. Esta situación llevó a la generalización de un profundo malestar en sectores internos del partido gobernante (Partido Justicialista, PJ en adelante) que empezaron, desordenadamente, a plantearse la disyuntiva de abandonar el PJ o quedarse para dar en su interior la lucha política frente a un gobierno que parecía, a su entender, haber abandonado la búsqueda de la justicia social que había definido durante casi medio siglo al peronismo.

En este marco, dentro de la Cámara de Diputados, comenzaron a agruparse ocho legisladores peronistas que provenían de los sectores de izquierda de la renovación ${ }^{2}$ y

La versión original de este trabajo fue presentada al XXI Congreso Internacional de LASA, realizado en Chicago del 24 al 26 de septiembre de 1997 con el título Old and New Actors in the Postmenemist Scenery: From Evita to Graciela, the Experience of Frente Grande/Frepaso. Debo hacer explícita mi deuda con Franco María Castiglioni (UBA), Jean Francois Prud'homme (COLMEX) y Fabián Repetto (UBA-USA), quienes comentaron distintas versiones de este trabajo.

** Profesor de Teoría Política Contemporánea y de Introducción a la Ciencia Política en la Universidad de Buenos Aires. Candidato a Doctor por el Programa de Doctorado de Investigación en Ciencia Política ofrecido por FLACSO-México. Actualmente se desempeña como investigador visitante en el Departamento de Gobierno de la Universidad de Georgetown[冈]uanAbal@compuserve.com].

1. Si bien en su campaña electoral Carlos Menem había recurrido a todo el imaginario discursivo del peronismo histórico, con promesas del tipo de "el salariazo" y "la revolución productiva", una vez en el gobierno convocó a formar parte de su administración a grupos vinculados al gran empresariado y a sectores de la dirigencia conservadora tradicionalmente anti-peronistas. A esto se le sumó un claro posicionamiento internacional a favor de los intereses norteamericanos en visible contraste con la tradición justicialista de la "tercera posición" y una política económica de signo liberal ortodoxo que contrastaba con el discurso estatista e industrialista que habían profesado todas las versiones previas del peronismo.

2. La llamada renovación peronista fue una corriente interna del PJ que se constituye después de la primera derrota electoral del justicialismo en 1983 con el objetivo de obtener la conducción partidaria, democratizar los procedimientos internos y actualizar el ideario partidista. Si bien Carlos Menem fue uno de los dirigentes más importantes de este sector al 
que empezaron a tomar medidas autónomas del bloque oficialista. En enero de 1990 estos ocho legisladores emitieron una declaración contraria a "la alianza con el liberalismo" (Clarín, 19/1/90), y poco después se opusieron activamente a la privatización de la empresa nacional de ferrocarriles y al proyecto del ejecutivo para ampliar el número de integrantes de la Corte Suprema de Justicia.

En junio de ese mismo año, estos legisladores, que habían pasado a denominarse el Grupo de los Ocho, convocaron a un encuentro nacional de la militancia peronista opuesta a las políticas implementadas por el presidente Menem en la localidad de Villa María (Córdoba), con la consigna de "Peronismo o Liberalismo, para recuperar el verdadero peronismo". Las declaraciones del encuentro expresaban la idea de "recuperar para el peronismo su carácter revolucionario y transformador frente a la victoria popular del 14 de mayo” (Clarín, 3/5/90).

Entre los convocantes del encuentro se destacaron los diputados: Carlos "Chacho" Álvarez, dirigente de una agrupación del PJ de la Ciudad de Buenos Aires llamada, Movimiento Renovador Peronista (MRP, en adelante); Germán Abdala, dirigente del gremio porteño de trabajadores estatales; Juan Pablo Cafiero, hijo del derrotado líder de la renovación y dirigente de la Provincia de Buenos Aires, al igual que Luis Brunati.

En este encuentro se creó una corriente interna, denominada Corriente Nacional y Popular, cuyo propósito público era disputar la conducción del peronismo. Como acción inaugural presentan en el parlamento un proyecto en contra del indulto presidencial a los responsables del terrorismo de Estado. Pero más allá del entusiasmo inicial, la corriente afronta problemas serios, tanto externos como internos, al no poder sus dirigentes acordar una política clara a seguir. Quizás la condición de pares que les daba su origen legislativo, sumado a la ausencia de dirigentes con proyección nacional, conspiró contra el establecimiento de un liderazgo claro. Así, en el año 1991, los distintos grupos fueron abandonando desordenadamente el PJ y constituyendo (proto) partidos, entre los que se destacaron el grupo proveniente del MRP que funda el MODEJUSO con Chacho Álvarez como presidente y el de los militantes cercanos a Luis Brunati que constituyen el Encuentro Popular.

Las elecciones de 1991 representaron para los peronistas opositores una oportunidad importante, en tanto ellos creían que el "pueblo peronista" iba a castigar en las urnas a quienes en su nombre estaban llevando adelante una política económica neoliberal, la llamada "traición" de Menem. A esta idea se sumaba que la economía argentina aún no salía del caos generado durante la pasada década. Sin embargo, los problemas de liderazgo antes señalados hicieron imposible la construcción de una opción electoral única y los grupos del peronismo opositor se presentaron divididos en una serie de frentes electorales con pequeños partidos del espectro político de la izquierda y el centroizquierda.

En la Capital Federal acudieron dos frentes a las elecciones: el FREDEJUSO, constituido por el MODEJUSO de Chacho Álvarez junto con el Partido Intransigente, que había sido un importante referente del centroizquierda en los primeros años de los ochenta y un grupo de políticos
TABLA 1

\begin{tabular}{|l|c|c|}
\hline \multicolumn{3}{|c|}{ REsultados ELECTORALES NACIONALES } \\
\hline Año y tipo de elección & $\begin{array}{c}\text { Resultados nacionales } \\
\text { (cargos obtenidos) }\end{array}$ & Denominación partidaria \\
\hline 1991 Legislativa & $1,4 \%(0)$ & FREDEJUSO \\
\hline 1993 Legislativa & $3,6 \%(3)$ & Frente Grande \\
\hline $\begin{array}{c}1994 \text { Convencionales } \\
\text { Constituyentes }\end{array}$ & $12,7 \%(31)$ & Frente Grande \\
\hline $\begin{array}{l}1995 \text { Presidencial } \\
1997 \text { Legislativas }\end{array}$ & $28,8 \%(0)$ & FREPASO (FG, PAIS, US) \\
\hline 1998 Primaria presidencial & $45,6 \%(61)$ & Alianza (UCR,FREPASO) \\
\hline
\end{tabular}

progresistas, entre los que se destacaban Carlos Auyero, proveniente de la Democracia Cristiana y la dirigente de los derechos humanos Graciela Fernández Meijide, postulando a esta última como primera candidata a diputada ${ }^{3}$. Por otro lado el grupo orientado por Luis Brunati se presentó como Frente Popular junto con grupos de izquierda llevando como primer candidato a un conocido actor progresista, Norman Briski. En la provincia de Buenos Aires algunos sectores se encolumnaron detrás de la candidatura a gobernador de Saúl Ubaldini, sindicalista opositor a Menem, mientras que otros, que se habían agrupado alrededor de Juan Pablo Cafiero, constituyeron junto con el Partido Intransigente la versión provincial del FREDEJUSO.

Los resultados de la elección no pudieron ser peores para los grupos peronistas disidentes, ya que el PJ obtuvo una resonante victoria nacional que empalideció aún más la pobre adhesión por aquellos conseguida. Quizás deba destacarse que el FREDEJUSO capitalino consiguió ubicar a su primer candidato, Aníbal Ibarra, como concejal porteño ${ }^{4}$.

Divididos en pequeños grupos, con votaciones semejantes a los partidos de la izquierda tradicional y frente a un PJ victorioso, el porvenir de los disidentes del peronismo no podía aparecer más incierto. Asimismo, en alguna parte de su trayecto habían perdido el discurso del "verdadero peronismo" y no parecían saber qué representaban, si es que representaban algo, en la política argentina. Carlos "Chacho" Álvarez definió a los años que él y sus compañeros vivieron desde el momento que se fueron del PJ hasta fines de 1993 como "el desierto", haciendo referencia a la soledad y la dificultad que da vivir en los márgenes de la política.

aproximarse la elección interna que decidiría al candidato presidencial del peronismo abandona este grupo, que postulaba al máximo referente de la corriente Antonio Cafiero, y junto con los sectores más tradicionales del partido, llamados "ortodoxos", gana esas elecciones primarias.

3. El grupo político orientado por Carlos Auyero se autodenomi naba Partido Democracia Popular y bregaba desde su origen por la uni dad del "espacio progresista" para conformar un frente social en oposición a las reformas neoliberales implementadas por el gobierno.

4. Para no confundir al lector con siglas y cifras comentamos al pie de página los resultados de los comicios. Mientras el PJ obtuvo un total nacional del 40,4\%, lo que le significó la consolidación de su mayoría en las cámaras legislativas y el control de la mayor parte de las gober naciones, los grupos que después constituirían el Frente Grande figuraron en el rubro "otros" por sus insignificantes votaciones. Así en la Capital Federal la candidatura de Fernández Meijide por el FREDEJUSO alcan zó el 3,6\% de los votos válidos, mientras que el Encuentro Popular consiguió el 1,3\%. En la provincia de Buenos Aires el FREDEJUSO logró un $2,5 \%$ y la Acción Popular por la Liberación que postulaba a Ubaldin el 2,2 \%. Al final del presente trabajo se detallarán todos los resultados electorales. 
Tras el rotundo fracaso experimentado en las elecciones de 1991, los diversos grupos de la disidencia peronista vivieron una situación difícil. Algunos retornaron al PJ, otros abandonaron la política y sólo unos pocos siguieron buscando construir una opción de poder. Los sectores del FREDEJUSO de Álvarez iniciaron desde principios del año 1992 una serie de llamamientos a la unidad de las fuerzas de centroizquierda, especialmente dirigidos a los centenarios partidos socialistas argentinos's. Su propuesta era construir un frente electoral para las elecciones que, en junio de ese año, designarían a un senador por la Ciudad de Buenos Aires.

Paralelamente a los intentos de Álvarez, otro sector de la disidencia peronista, el del Encuentro Popular de Brunati, buscó construir también un frente electoral para esas elecciones pero desde una posición ubicada más a la izquierda. Así constituyeron, junto con el Partido Comunista, el Frente del Sur el cual postuló como candidato a senador al cineasta peronista Fernando "Pino" Solanas. Los fracasos de Álvarez en conseguir que los socialistas acepten integrar un frente, lo llevaron a apoyar a regañadientes la candidatura de Solanas, que obtuvo casi un ocho por ciento de los votos, muy por detrás de los dos partidos mayoritarios ${ }^{8}$.

Después de estas elecciones se acentuaron los contactos entre el grupo de Álvarez y el Frente del Sur, especialmente en el ámbito universitario? ${ }^{7}$ Hacia fin de año, en octubre, el FREDEJUSO, realizó su primer congreso, que culminó con un llamado a la unidad del "espectro progresista".

La coyuntura del año 1993 llevó a que los actores deban organizarse con vistas a las elecciones de renovación parlamentaria de fin de año. La mala experiencia de la elección anterior predispuso a los disidentes peronistas y a sus aliados a dejar de lado las rencillas y buscar la unidad. Es en este marco que a principios de abril de 1993 se constituye el Frente Grande, como fusión de los dos frentes anteriores más otros grupos pequeños realizándose el lanzamiento oficial el 27 de ese mismo mes, en un conocido café del centro porteño.

Internamente el Frente Grande estaba muy lejos de ser una organización, sus distintos componentes no tenían demasiado claro cual era su situación interna y sólo la necesidad de presentarse a elecciones los llevó a unificarse. En su interior se destacaba el grupo de Álvarez, con un proyecto de tinte socialdemócrata, frente al sector que se agrupaba alrededor del ex candidato a senador Solanas, con un discurso más radical de tipo nacionalista y de izquierda. La discusión programática logró evitarse con un parejo reparto de cargos en las listas electorales que dejó para más adelante la supuesta interna abierta de la que se había hablado al constituirse el nuevo frente.

\section{EL FRENTE GRANDE, EL FREPASO Y LA ALIANZA}

Las elecciones legislativas de octubre de 1993 ocupan un lugar central a la hora de comprender la posterior trayectoria del Frente Grande. El resultado de la votación excedió los pronósticos más optimistas del FG: la boleta para diputados nacionales capitalinos encabezada por Álvarez obtuvo casi el quince por ciento de los sufragios, manteniéndolo en la Cámara de Diputados, a la que también consiguió ingresar Fernández Meijide que lo secundaba en la lista; asimismo obtienen cuatro concejales ${ }^{8}$. En la Provincia de Buenos Aires la candidatura de Solanas alcanzó el 4,1\%, con lo que el cineasta también pudo hacerse con una banca ${ }^{9}$.

Tres elementos hicieron que esta elección fuera fundamental para el posterior desarrollo del FG. Primero, en términos de la opinión pública, el partido fue presentado como uno de los ganadores de la elección por varios medios de comunicación masivos, iniciándose un "romance" entre ellos y el Frente que continuará, aunque con altibajos, durante los años posteriores y que influirá notoriamente en las decisiones futuras del partido.

En segundo lugar, en el plano de cuestiones endógenas, las elecciones desnivelaron el precario equilibrio interno del FG a favor del grupo de Álvarez por sobre el de Solanas. "El Chacho" se convirtió en la cara visible del fenómeno electoral y su discurso de tinte socialdemócrata fue presentado como la nueva izquierda moderna del país.

Finalmente, el impacto que estas elecciones tuvieron sobre el tradicional partido opositor, la Unión Cívica Radical, fue devastador. Si bien en números reales la UCR no había hecho una mala elección, su derrota en la Capital Federal, primera que sufría desde el año de 1973, y la ventaja que le había sacado el candidato justicialista en la Provincia de Buenos Aires, pusieron al centenario partido en los ojos de la opinión pública como el claro perdedor de los comicios, e internamente la sumergieron en una situación de desánimo tal que sus dirigentes no se sintieron capacitados para resistir los intentos de reelección del menemismo.

Desde el Poder Ejecutivo los brillantes resultados del oficialismo (el 43,4\% del total nacional de votos) fueron leídos como una oportunidad para avanzar con un plebiscito sobre la posibilidad de reformar el texto constitucional con el objeto de habilitar la reelección del presidente. En este escenario, la UCR se sintió impotente y desconcertada, situación que fue aprovechada por el ex presidente Alfonsín para retomar la conducción partidaria y desde ahí firmar un

5. Los dos principales partidos que se reivindicaban como parte del "viejo tronco socialista" eran el Partido Popular Socialista, importante en la provincia de Santa Fe, y el Partido Socialista Democrático, con algún desarrollo en la ciudad de Buenos Aires. Ambos desde los ochenta habían constituido una alianza llamada "Unidad Socialista".

6. Los resultados de las elecciones dieron la victoria al candidato radical, Fernando De la Rúa con el $49,88 \%$ de los votos. En segundo lugar quedó el PJ con el $31,80 \%$, seguido, muy por detrás, por el Frente del Sur con el 7,44\% y por el MODIN, del exgolpista Aldo Rico, con el 5,63\%.

7. En las elecciones de noviembre de 1992 de la politizada Facultad de Ciencias Sociales de la Universidad de Buenos Aires se presentaron unidos por primera vez los seguidores de ambos grupos (MOVES).

8. El Frente Grande obtuvo el $13,4 \%$ de los sufragios, aunque lejos de la UCR $(29,4 \%)$ y del PJ $(31,9 \%)$ pero por encima de la Unidad Socialista $(4,2 \%)$ y de los demás partidos.

9. La elección de la Provincia de Buenos Aires resulta importante para comprender los posteriores movimientos internos que se dieron en el Frente. Su resultado es claramente opacado por el de la Capital, especialmente al no lograr que entre el segundo candidato a legislador, Luis Brunati, quien era una pieza fundamental del sector "antichachista" o "de izquierda” del Frente y que tiempo después abandonaría la política. Según el acuerdo interno del FG a cada grupo le correspondían dos diputados nacionales. Además el 4,1\% obtenido lo coloca por detrás del ultraderechista MODIN que obtuvo el 10,6\% de los votos. 
sorpresivo acuerdo con Menem, llamado "Pacto de Olivos", que abrió la puerta a una reforma de la Constitución.

Mucho se ha escrito acerca de los motivos del acuerdo UCR - PJ (Acuña, 1995). Para lo que a nosotros nos interesa aquí significó una especie de suicidio político en el corto plazo para el partido radical y una brillante oportunidad para el Frente Grande de convertirse en la principal oposición, oportunidad que Álvarez no estaba dispuesto a perder.

Así, para las elecciones de Convencionales Constituyentes del 14 de abril de 1994, el FG abrió sus listas a diferentes figuras de la intelectualidad y de las organizaciones sociales progresistas. Como ya era tradición Álvarez volvió a ofrecer a los socialistas constituir una oferta electoral común, estando dispuesto, incluso, a cederles el primer lugar en la Capital. Como también era costumbre, los socialistas rehusaron el ofrecimiento.

La vacancia de oposición fue así ocupada por el Frente Grande que pronto se colocó en el papel de principal impugnador del "pacto bipartidista". Lo hizo apelando, por un lado, "a la oposición más frontal al gobierno en el terreno republicano y de la independencia de los poderes, centrado en particular en la denuncia de la corrupción" (Abal Medina y Castiglioni, 1997) a la vez que moderando su discurso económico, en un momento en el que la economía argentina atravesaba una fase de inédita estabilidad de precios y fuerte crecimiento del producto bruto.

Los resultados electorales dan cuenta de una magnífica votación para el FG, que ganó la Capital, encabezado por Álvarez, y la provincia de Neuquén (con la candidatura del obispo retirado Jaime de Nevares, conocido defensor de los derechos humanos) a la par que obtiene el segundo lugar en la provincia de Buenos Aires desplazando a la lista del radicalismo encabezada por el ex presidente Alfonsín, al tercer lugar ${ }^{10}$. Consigue treinta y un convencionales constituyentes que sí bien eran pocos para evitar la consagración del Pacto de Olivos, sí eran suficientes para plantear sus iniciativas y hacerse notar con fuertes reclamos en torno de la calidad de las instituciones democráticas y de los equilibrios republicanos.

Frente a los resultados obtenidos por el FG, es lícito preguntarse ¿por qué los votos de oposición al menemismo confluyeron en una fuerza que tenía por principal candidato a un ex-peronista como Carlos "Chacho" Álvarez, aliado a pequeños sectores de izquierda?. Gran parte de la explicación radica en aquellos que fueron elegidos por Álvarez como destinatarios de su propuesta. Estos fueron no solo los afectados por el modelo económico, como en el discurso clásico de la izquierda y del peronismo "verdadero" sino, ante todo, los ciudadanos cansados de la corrupción y la estética frívola y triunfalista con la que estaba asociado el menemismo. Esta moderación discursiva se fue incrementando al compás de la campaña electoral, incluso el mismo día de la elección Álvarez declaró a la prensa: "la estabilidad es algo que no debe discutirse (...) no puede volverse atrás con las privatizaciones" (Clarín:11/4/94).

El Frente Grande fue rápidamente identificado con la figura de "Chacho" Álvarez y éste con un nuevo estilo de oposición, cuya credibilidad reposaba en la intransigencia en el plano ético-cultural y, al mismo tiempo en un realismo económico, poco alineado al rótulo izquierdista que le asignaban los analistas políticos, que acentuaba la crítica a la desigualdad en el reparto del ingreso por sobre la denuncia al "modelo" económico en su conjunto.

El éxito obtenido por el FG desde 1993 hubiese sido impensable sin la centralidad que adquirieron los medios de comunicación en la vida de la gente, lo que permitió sortear los pequeños aparatos militantes, y el discurso ideológico de algunos de los sectores que conformaban el partido. Sin recursos y con escasa estructura de activistas - pero con exitosa performance mediática- esta nueva fuerza política se instaló velozmente. En palabras de Cheresky (1994) “...el eco de las apariciones de Carlos Álvarez le permitió desarrollar autónomamente su discurso legitimándolo cada vez con el éxito mediático y prescindiendo en buena medida de acuerdos con aquellas agrupaciones que constituían formalmente la etiqueta partidaria. Sin esa relación directa con una audiencia, el éxito del Frente Grande... hubiese sido impensable...".

Dentro del bloque del FG en la Convención Constituyente, que sesionó entre mayo y agosto de 1994, se dieron una serie de discusiones que reflejaban la disputa interna sobre la orientación programática del joven partido. Los planteamientos más radicales de Solanas fueron perdiendo fuerza frente al discurso moderado de Álvarez. Estos enfrentamientos continuaron y se incrementaron al finalizar las sesiones de la Convención Constituyente ${ }^{11}$

En los meses finales de 1994 se produjo una visible transformación en el FG que, de la mano de Álvarez, modera aún más su discurso e inicia acciones para constituirse como partido político. El 8 de agosto se llevó a cabo un encuentro en la Confitería del Molino, del que participaron, además de Álvarez, Federico Storani de la UCR, y José Bordón del PJ, con el fin de construir un espacio transversal para derrotar al menemismo.

En noviembre de ese año Fernando Solanas, cada vez más molesto con las políticas del FG, especialmente por la reivindicación que hace Álvarez de la política económica del gobierno (Clarín: 9/9/94) y por el papel secundario que el nuevo estado de fuerzas internas le otorgaba, abandona el Frente y constituye un nuevo espacio político llamado Alianza Sur, siendo acompañado por muy pocos de sus antiguos aliados. De esta manera se cierra el conflicto programático que existía desde la constitución del FG entre los que provenían del FREDEJUSO y, buscaban construir una opción de centroizquierda o "progresista", y los que provenían del Frente del Sur y pretendían convertirse en una

10. En los totales nacionales la UCR mantuvo el segundo lugar con un $20,5 \%$, lo que representó menos de la mitad de los votos obtenidos por el oficialismo $(43,4 \%)$ y la votación más baja de su historia hasta esa fecha. El Frente Grande obtuvo un total nacional del 12,7\% constituyéndose en la tercera fuerza electoral. Junto con los altos resultados obtenidos en la Capital (36\%), Neuquén $(29,8 \%$ ) y Buenos Aires (16\%) deben destacarse los de varias provincias donde hasta entonces el Frente no existía como Río Negro (9,7\%), Entre Ríos (12,5\%) y Santa Fe (10,2\%).

11. Así Álvarez, por ejemplo, pretende obligar al Partido Comunista a disolverse o a cambiarse de nombre, señalándole que si no lo hace deberá abandonar la coalición. Finalmente, el PC se va del Frente en agosto de 1994, aunque muchos de sus cuadros y dirigentes se quedan constituyendo diversas agrupaciones al interior del FG. 
fuerza de izquierda que condenara globalmente al modelo económico ${ }^{12}$.

En la última parte de 1994 los acontecimientos se aceleraron y en diciembre se concretó la creación del FREPASO, "Frente por un País Solidario". Participaron en este nuevo frente, además del FG, el ya mencionado Bordón, quien había abandonado el PJ en septiembre y fundado su propio partido, "PAIS", los socialistas ya convencidos de los costos de mantenerse al margen del resto del espacio, y otros partidos menores. Poco después se sumaban al FREPASO un grupo de militantes radicales dirigidos por Carlos Raimun$\mathrm{di}^{13}$. Se decide elegir la fórmula presidencial mediante primarias abiertas que se realizaron el 26 de febrero de 1995 y en las que compitieron Álvarez y Bordón.

En esa elección participaron cerca de medio millón de ciudadanos resultando ganador, por un muy escaso margen, Bordón. Mucho se ha hablado de esta interna, pero lo cierto es que la nueva candidatura, potenciada por la sorpresa del resultado, despertó una enorme expectativa y empezó a crecer en las encuestas mientras se desplomaba, literalmente, la fórmula de la UCR. El discurso del FREPASO dominante en la campaña electoral, salvo alguna esporádica jerarquización de intereses e instrumentos, mantuvo su carácter fuertemente "moral" buscando diferenciarse del "costo social del ajuste" y de la "corrupción del gobierno" con la propuesta central de "un mejor gobierno". Al mismo tiempo, el candidato presidencial del FREPASO renovaba su compromiso con la estabilidad económica y la convertibilidad de la moneda (Clarín:7/4/95).

Las elecciones del 14 de mayo le dieron la reelección a Menem pero colocaron al FREPASO en un cómodo segundo puesto. Por primera vez en sus cien años de historia la UCR era desplazada al tercer lugar ${ }^{14}$. Este enorme caudal electoral no se correspondía con los espacios de administración que controlaba la fuerza. Por ello se volvió prioritario para el FG/Frepaso obtener la victoria en las próximas elecciones del intendente de la Ciudad de Buenos Aires, capital y vidriera política del país.

Sin embargo, el desorden interno de la fuerza complicó la tarea. Así, estaba planeada una elección interna del FREPASO en agosto para elegir al candidato a intendente entre el popular ex fiscal Aníbal Ibarra por el FG y Norberto La Porta por los socialistas. Pero estas elecciones no se realizaron al renunciar Ibarra sorpresivamente a su candidatura por motivos que no quedaron del todo claros. De esta manera La Porta resulta ser el candidato, debilitando las posibilidades electorales de la fuerza.

En octubre se realizaron los comicios para elegir el tercer senador por la capital. En ellas, el FREPASO con la candidatura de Fernández Meijide obtuvo un resonante triunfo al superar el cuarenta y cinco por ciento de los votos. Graciela, como la llamaron los medios, quien antes de esta elección no disfrutaba de una alta popularidad, se transformó en un nuevo fenómeno sin equivalentes en la política argentina. Esta elección tuvo una enorme importancia para el FG en términos de su fortalecimiento como opción política ya que significó la primera victoria electoral sin la candidatura de Álvarez y sobre un candidato radical no comprometido con el Pacto de Olivos. Así quedó claro que el Frente era algo más que la expresión de una persona y del descontento con la UCR por su acercamiento al gobierno de Menem.

Los sucesos que condujeron a la salida de Bordón del FREPASO se desencadenaron con los intentos de éste, en febrero de 1996, de reabrir la elección primaria para la candidatura a la intendencia y postular al ex ministro del interior de Menem, Gustavo Béliz. Esta idea encuentra la cerrada oposición de los socialistas y de la enorme mayoría de la militancia del FG encabezada por Fernández Meijide. Finalmente, el 9 de febrero de 1996, Bordón se aleja del FREPASO esperando capitalizar a su favor la enorme popularidad que las encuestas de opinión le otorgaban, hasta entonces superior a la de Álvarez, y los cinco millones de votos obtenidos por su candidatura pocos meses atrás.

Sin embargo, la recepción que la ruptura encuentra en la opinión pública y en la militancia del FREPASO, incluso en la de su partido PAIS, demuestran lo errado del juicio de Bordón, quien termina renunciando a su banca en el Senado en un gesto desesperado por recuperar credibilidad. La jugada de Bordón no tomó en cuenta que el FG, a pesar de su débil institucionalización, era ya un organización política anclada en un gran sector de la población y, por ende, capaz de superar derrotas y problemas internos. Es demasiado fácil acusar a Bordón de miopía política a la luz de los acontecimientos posteriores, sin embargo, se debe recordar que en aquella época un sector importante de los analistas y los políticos consideraban al FG/Frepaso como un flash party, o sea una opción política destinada a desaparecer con la misma velocidad con que había surgido, entendiéndolo como la simple expresión del malestar ciudadano, de carácter momentáneo, con la corrupción menemista y con el Pacto de Olivos ${ }^{15}$. Los sucesos posteriores a la salida de Bordón demuestran, por el contrario, que el FG/Frepaso era un

\section{TABLA 2}

\begin{tabular}{|c|c|c|}
\hline \multicolumn{2}{|c|}{ Resultados ELECTORALES NACIONALES DE LA CAPITAL FEDERAL (Ciudad de Buenos Aires) } \\
\hline Año y tipo de elección & Resultados nacionales & Denominación partidaria \\
\hline 1991 Legislativa & $3,6 \%$ & FREDEJUSO \\
\hline 1992 Senador & $7,44 \%$ & Frente del Sur \\
\hline $\begin{array}{c}1993 \text { Legislativa } \\
\text { 1994 Convencionales } \\
\text { Constituyentes }\end{array}$ & $13,4 \%$ & $\begin{array}{c}\text { Frente Grande } \\
\text { (FREDEJUSO y frente del Sur) }\end{array}$ \\
\hline 1995 Presidencial & $36,1 \%$ & Frente Grande \\
\hline $\begin{array}{c}1996 \text { Convencionales } \\
\text { Estatuyentes } \\
\text { Intendente }\end{array}$ & $44,2 \%$ & FREPASO (FG, PAIS, US) \\
\hline 1997 Legislativas & $34,7 \%$ & FREPASO \\
\hline 1998 Primaria presidencial & $26 \%$ & FREPASO \\
\hline
\end{tabular}

12. Estas discusiones se reflejaban en el contexto internacional, así los dirigentes cercanos a Álvarez se identificaban con los partidos socialdemócratas europeos, y sus opositores miraban con buenos ojos a los partidos del Foro de San Pablo, en particular, al Partido de los Trabajadores de Lula.

13. Posteriormente se sumarán otros dirigentes radicales importantes entre los que destaca Dante Caputo, quien había sido Canciller del gobierno de Raúl Alfonsín.

14. Los resultados de estas elecciones fueron: PJ 50\%, FREPASO $28,8 \%$ y UCR $16,9 \%$.

15. Ver al respecto Abal Medina (1998). 
fenómeno radicalmente distinto a las terceras fuerzas que habían surgido anteriormente en la historia argentina.

Finalmente, el 30 de junio de 1996 tienen lugar las elecciones a intendente en la capital, en forma conjunta con la de Convencionales Constituyentes locales. En ellas, si bien el FREPASO, otra vez con Fernández Meijide, logra ganar la elección de constituyentes, pierde la intendencia en manos de Fernando De la Rúa, el candidato de la UCR, poniendo fin a una serie de tres triunfos consecutivos en esa ciudad. Esta importante derrota pone al FG en un estado de discusión interna, a partir de la cual los distintos grupos deciden avanzar en la postergada institucionalización del partido.

A principios de diciembre se realiza el Primer Plenario Nacional del FREPASO que decide convertirse en "confederación de partidos” y nombrar una Junta Confederal Nacional compuesta por los representantes de los siete partidos que lo forman. Algunos días después el FG realiza en la ciudad de Buenos Aires sus primeras elecciones internas que más allá de la escasa participación que obtiene, cuatro mil personas, sirven para que al fin la fuerza se transforme, por lo menos oficialmente, en un partido político. Posteriormente se realizan elecciones internas en las provincias de Buenos Aires y Córdoba, con una mayor participación: veinticinco mil votantes en la primera y dieciocho mil en la segunda.

El año de 1997 estuvo marcado desde el principio por las importantes elecciones de renovación parlamentaria que se llevarían a cabo en octubre de ese año. El FREPASO decide sorpresivamente impulsar a Fernández Meijide como primera candidata en la provincia de Buenos Aires, principal distrito electoral del país gobernado por el más fuerte candidato presidencial del justicialismo, Eduardo Duhalde.

La candidatura de Fernández Meijide y cierta sensación de hartazgo moral con el menemismo, sumados a la prepotencia que el PJ desplegaba en los medios de comunicación por esos días, llevan a que se realice, en agosto, algo impensable días atrás: la unidad de los dos principales partidos de la oposición, la UCR y el FREPASO en la Alianza por el Trabajo, la Justicia y la Educación. Las complejas negociaciones para el reparto de los cargos culminan con las candidaturas de las dos máximas figuras del FG, Álvarez y Fernández Meijide en la Capital y en la provincia de Buenos Aires respectivamente. Asimismo, ambas fuerzas se comprometen a decidir mediante una primaria abierta la fórmula presidencial común para 1999.

Gráfico I: Resultados electorales totales nacionales y Capital Federal

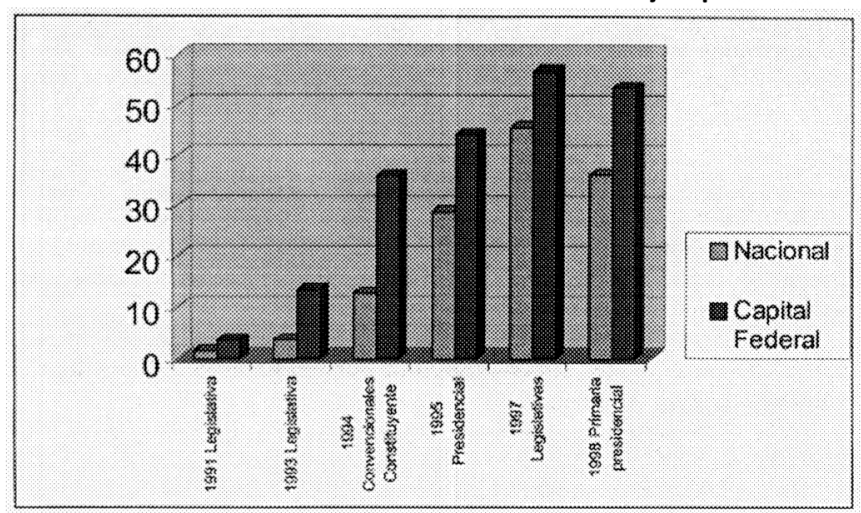

La conformación de la Alianza parece nuevamente remarcar un extraño rasgo político que el FG ha mostrado desde sus orígenes, al privilegiar los intereses visualizados como generales sobre los particulares. De la misma manera que Álvarez se cansó de ofrecer la unidad a los socialistas en los primeros años de la década del noventa o que abrió su fuerza a Bordón a fines de 1994, la unidad con la UCR se realiza en un momento en el que el FG tenía todo para ganar, cuando sus candidatos superaban cómodamente en los sondeos de opinión a los del radicalismo en los dos principales distritos del país. Sin embargo, la necesidad de derrotar al oficialismo rompiendo "el juego de suma cero" (Abal Medina, 1995) en el que parecía estar la oposición pesó más en los lideres del FG que las conveniencias propias.

La Alianza consiguió el 26 de octubre una importante victoria en todo el país poniendo fin a diez años de predominancia del PJ ${ }^{16}$. Especialmente notoria fue la victoria de Fernández Meijide en la Provincia de Buenos Aires, bastión histórico del justicialismo ${ }^{17}$, quién es proclamada rápidamente candidata presidencial del FREPASO para la interna de la Alianza.

El año 1998 comenzó con problemas internos entre los partidos de la Alianza vinculados a la fecha y la forma que se realizaría la interna abierta y a las relaciones entre la administración de De la Rúa, candidato oficial de la UCR para la interna de la Alianza, y la Legislatura porteña dirigida por el FG/Frepaso.

Básicamente el FG/Frepaso percibía que la lucha interna sería enormemente desigual al tener que enfrentar a la poderosa organización territorial del radicalismo. Los conflictos se agudizaron hacia mediados de año por algunos hechos de corrupción de personas cercanas al candidato radical y a la utilización que éste hacía de la propaganda del gobierno de la Ciudad de Buenos Aires.

Los problemas internos exhibidos por la Alianza tuvieron su mayor impacto en la débil y desordenada respuesta que dieron a los intentos del presidente Menem de forzar, mediante la Corte Suprema de Justicia, la Constitución para obtener la posibilidad de presentarse a un nuevo mandato presidencial. Llamados a constituir ámbitos plurales en defensa de la Constitución fueron perdiendo relevancia con las continuas peleas respecto a quienes se debía convocar. Finalmente, la Alianza fue sorprendida por la fuerte reacción del gobernador Duhalde quien, con la convocatoria a un plebiscito sobre la re-reelección en la provincia de Buenos Aires, fuerza a Menem a renunciar públicamente a intentar un nuevo mandato presidencial.

Cuando se aproxima la elección interna del 29 de noviembre nuevas dificultades sacuden a la Alianza y en muchos sectores se expresan serias dudas sobre su futuro.

16. Los resultados nacionales fueron: $36,4 \%$ para la Alianza, lo que sumado al 6,8\% de la UCR y al 2,4\% del FREPASO obtenidos en los distritos donde no se conformó la alianza dan una votación total del $45,6 \%$ y logran 61 escaños contra el $36,2 \%$ y los 51 obtenidos por el oficialismo en la Cámara de Diputados.

17. En la provincia de Buenos Aires la Alianza se impone por siete puntos al PJ, 48,29 a 41,32. También muy importante para el FG/Frepaso es la victoria obtenida en la provincia de Neuquén donde se impone presentándose separado de la UCR. 
Especialmente importantes fueron los planteamientos hegemónicos de ciertos sectores del radicalismo que parecían creer que la unidad con el FREPASO era sólo un mal necesario para mejorar su perfil frente a la opinión pública y, a partir de allí, reposicionarlos en el sistema argentino de partidos. La cúpula del FG/Frepaso, Álvarez y Fernández Meijide, se manifiesta preocupada por el porvenir de la fuerza si en las elecciones internas el fuerte peso del aparato partidario radical coloca a De la Rúa como candidato presidencial sin que haya un previo reparto equitativo de los espacios institucionales de poder. Sin embargo, el poder del justicialismo no deja muchas dudas de que, de romperse la Alianza y competir sus dos partes separadamente en las elecciones del año próximo, la Argentina comenzará el próximo milenio con otro presidente peronista.

Los problemas que debe afrontar el FG/Frepaso son difíciles. Principalmente el FG, grupo central del FREPASO, está muy lejos de alcanzar los niveles de organización, estructura territorial y recursos militantes que caracterizan a cualquier partido político importante. A esto se suma que el partido de Álvarez no consiguió ganar siquiera en una pequeña intendencia en todo el país. Sólo la municipalidad de Rosario, en manos de los socialistas del PSP y dos municipios medianos cuyos intendentes se pasaron al FG, constituyen los lugares de gestión de la fuerza.

Este déficit interno se vuelve más notorio y grave por el hecho de compartir la Alianza con el partido radical, una organización que, a pesar de sus últimamente malos resultados electorales, tiene una estructura de recursos humanos y materiales que fácilmente multiplica los del FG/FREPASO. El radicalismo administra cinco provincias, la ciudad de Buenos Aires y 460 intendencias, además de dirigir la mayor parte de las universidades del país.

De mantenerse la elección primaria abierta en la fecha fijada (29 de noviembre) como mecanismo para definir la candidatura presidencial de 1999 es muy poco probable que el FG/FREPASO logre ganarla. Sin embargo como la historia de esta fuerza nos muestra, no es totalmente imposible.

\section{EL CASO A LA LUZ DE LA TEORÍA: ORGANI- ZACIÓN Y DISCURSO ${ }^{18}$}

En este apartado nos abocaremos a analizar las particularidades que presenta el FG, primero en términos programático-discursivos y posteriormente en cuanto a su organización. Brevemente podemos decir que en las dos dimensiones el partido inicia su vida con características propias muy marcadas que, en parte, fue perdiendo en su evolución posterior, para asemejarse hoy a los principales partidos del mundo.

El Frente Grande enfrenta el problema de su identidad discursiva y debe medirse con la necesidad de superar la fórmula fundada en la credibilidad del líder para expresar el clivaje ético del "cansancio moral" que lo llevó a instalarse en el sistema político ${ }^{19}$. La base social de referencia no está todavía identificada y tampoco puede contar con el imaginario ideológico de la tradición populista y revolucionaria de la izquierda argentina para representar a los actuales simpatizantes del Frente. Sólo en parte definiciones como "democracia con equidad", la apelación genérica al mundo de la producción y la reafirmación del rol del Estado para combatir la desigualdad, parecen dar sustento a un ideario progresista moderno que busca todavía una definición intelectual y política en la Argentina.

Por su prácticamente nula experiencia de gobierno, el FG/Frepaso, se enfrenta a las exigencias de un conjunto de organizaciones de intereses, factores de presión internacionales, y, desde luego, de la opinión pública, a dar pruebas de "responsabilidad", demanda que es, por razones de origen ideológico, muy apremiante y compleja. De allí, también, que esta fuerza tienda siempre más a suavizar los tonos de protesta, y conducirse a la búsqueda del voto centrista, que solicita orden, gobernabilidad, transparencia administrativa, eficientismo y pragmatismo, como es característico en las "democracias de la audiencia" (Manin, 1997): lo que frecuentemente muchas fuerzas políticas, de signos ideológicos distintos, traducen en una genérica “oferta” de buena administración y capacidad técnica. Sin embargo la moderación permanente del discurso, que vemos en la fuerza desde 1993, ha despertado fuertes críticas en su militancia y en sus electores más cercanos que señalan, con cierta dosis de verdad, algo de "peligrosa sobreactuación" en la relación del Frente con los factores de poder.

En términos organizativos el Frente Grande está pagando muy cara su opción por la construcción política a través de liderazgos massmediáticos y su ininterrumpida carrera electoral que lo llevó a privilegiar permanentes frentes electorales por sobre la construcción de instituciones sólidas o, en palabras del ya fallecido dirigente Carlos Auyero, "construir el barco mientras se navega”. Sin duda, esto le dio, y le $\mathrm{da}$, ventajas en términos de su alta flexibilidad, de la libertad que gozan sus líderes y de no cargar con un pesado aparato territorial, que en los otros partidos siempre está tentado de entrar en prácticas corruptas. Sin embargo, el déficit del FG es producto de no haber podido construir una organización partidaria de nuevo tipo que mantuviera esas ventajas pero le sumara solidez y capacidad militante.

Si bien no están puestos en discusión, al menos en esta fase, los liderazgos de Álvarez y Fernández Meijide, el crecimiento político-organizativo de la fuerza está ligado al reordenamiento de su organización, de su identidad y de su propio papel. Se delinea el tradicional problema de la institucionalización de un movimiento carismático, o como recuerda Panebianco, la transferencia de la lealtad desde el/los líder/es a la organización. Este punto es especialmente importante si entendemos la institucionalización partidaria en el sentido de una propiedad que puede ser definida como "el grado en el que un partido existe en la opinión

18. Gran parte de las ideas que se exponen en este apartado son fruto de largas discusiones y de un sólido trabajo conjunto entre el autor de este artículo y Franco María Castiglioni.

19. El clivaje ético-cultural de "cansancio moral" o de "gente común contra políticos” del que se aprovechó el FG/Frepaso puede ser comprendido como un cansancio general de los electorados frente a todos los partidos existentes y representa una polarización electoral que, por lo menos en parte, "deja de estar basada en la clase social y pasa a basarse en valores de tipo postmaterial” (Inglehart, 1990:279-280). 
pública, como organización social, aparte de sus líderes momentáneos" (Janda, 1993:167). En este sentido el partido está muy lejos de estar realmente institucionalizado.

En el FREPASO, por su carácter de confederación de partidos, la cuestión organizativa no ha superado más que el estadio de confederación donde un cuerpo directivo toma decisiones vinculantes por acuerdo. Sobre ellas se impone, por su carisma y por la innovación de la propuesta de ritmo vertiginoso y de permanente exposición pública, el liderazgo de Álvarez, que va desde la definición de alianzas, a las proposiciones tácticas, a la selección de candidatos independientes y a la producción de expresiones ciudadanas de protesta (Abal Medina y Castiglioni, 1999).

El FG se ha distinguido en términos organizativos por su carácter centralizado, personalista y mediático. Pero no ha establecido un modelo original de partido; al máximo, su irrupción repentina acentuó fuertemente características arraigadas en los partidos modernos, llamados "profesional-electorales” (Panebianco, 1990: 487-512). Superada la primera etapa en la que convivían desordenadamente rasgos de agencia electoral (Panebianco, 1990:511) con pretensiones de partido de masas la fuerza ha comenzado a transitar un lento camino de asimilación a los restantes partidos en el plano organizativo territorial, tendencia que se acentúa por encontrarse en una alianza electoral con un partido fuertemente estructurado, en la necesidad de afirmar base social e identidad y en la elaboración de programas moderados y pragmáticos.

Sin embargo, por el peso de su pasado reciente, por el tipo de recorrido abordado y por el ambiente externo en el que radica y compite, conforma su organización y su acción política con rasgos distintivos. De allí el exiguo número de afiliados y de militantes que convoca, el recurso permanente (a veces obsesivo) de los medios de comunicación, el centralismo más ágil para tomar decisiones, su flexibilidad a la hora de incorporar figuras independientes, como de hacer y deshacer alianzas y de promover procedimientos de acción política no convencionales.

\section{CONCLUSIÓN}

El Frente Grande ha comenzado paulatinamente a transformar, entre avances y resistencias, sus rasgos genéticos mayormente movimientistas y fuertemente críticos para tender hacia aquel patrón universal del partido electoral moderno, donde conviven el pragmatismo y la apelación directa al ciudadano por los medios, con una estructura territorial extendida en todo el territorio, multiplicidad de dirigentes reconocidos aunque centralizadores de decisiones y una definida base social de referencia desde donde capturar el voto centrista.

Así, a fines de siglo, esta fuerza representa una nueva opción política en su país y en América Latina, mezclando desordenadamente elementos de su vieja herencia populista con componente socialdemócratas y con fuertes matices propios. La próxima elección presidencial que enfrentará el FG en 1999 nos dirá qué tan lejos han llegado los disidentes de uno de los más grandes movimientos nacional populares de América Latina: el peronismo.

\section{POST SCRIPTUM}

El 29 de noviembre se realizaron las elecciones primarias abiertas para decidir el candidato presidencial de la Alianza. En ellas participaron cerca de dos millones y medio de ciudadanos, resultando vencedor el postulante de la UCR, Fernando De la Rúa quien ya es el candidato presidencial de la coalición. Las negociaciones post-electorales definieron que Carlos "Chacho" Alvarez acompañe a De la Rúa como candidato a vicepresidente y Graciela Fernández Meijide compita por la gobernación de la estratégica provincia de Buenos Aires.

Los resultados obtenidos por la candidata del FG/Frepaso, el 36,5\%, fueron muy inferiores a las estimaciones de sus colaboradores cercanos, pero reflejaron con transparencia la implantación territorial de la fuerza. Así, Fernández Meijide sólo se impuso en la Ciudad de Buenos Aires, distrito de nacimiento del partido, obtuvo resultados parejos en las provincias de Buenos Aires y Neuquén, pero fue superada por cifras aplastantes en la mayoría de los distritos del resto del país ${ }^{20}$. La elección puso en evidencia las debilidades estructurales del Frente. La enorme popularidad de la candidata y la confianza espontánea que genera en la ciudadanía llevaron al límite las posibilidades de la construcción política sin el sustento de los aparatos partidarios.

Sumado a lo anterior se debe destacar que la campaña electoral interna puso de manifiesto los serios problemas de identidad ideológica que el joven partido sufre. Algunas declaraciones desafortunadas de la candidata, por ejemplo sobre la conveniencia de ceder el control de la política social del Estado a la organización de caridad de la Iglesia Católica y ciertos intentos discursivos de transformar la debilidad organizativa de la fuerza mediante una campaña muy personalizada, generaron un notorio desencanto en los simpatizantes históricos del partido, muchos de los cuales se contentaron con concurrir a votar, muy lejos de los deseos de los dirigentes que confiaban en la tarea movilizadora de sus electores más fieles.

Sin embargo, contra lo que temían los dirigentes más pesimistas del Frepaso, la derrota de Fernández Meijide no significó un retorno de los planteos hegemónicos del radicalismo. La reciente e inesperada derrota de la UCR en la elección de gobernador de Córdoba, provincia que la que no perdía una elección desde 1973, si bien significó un fortalecimiento del justicialismo, al interior de la UCR sirvió como un poderoso llamado de atención a los sectores opuestos a la Alianza con el Frepaso que eran encabezados por el derrotado gobernador cordobés ${ }^{21}$. Después de este hecho ningún radical cree seriamente que su partido puede,

20. Como ejemplos de esto basta citar los casos de las provincias de: Chaco $(89 \%$ a $11 \%)$, La Rioja $(87 \%$ a $13 \%)$ y Catamarca $(86 \%$ a $14 \%$ ) donde el candidato radical casi obtuvo ventajas de 9 a 1 a su favor.

21. Desde un principio, el gobernador de Córdoba Mestre se opuso a la alianza de su partido con el Frepaso. Para demostrar la certeza de su opinión decidió adelantar las elecciones de gobernador, en las que las encuestas señalaban su segura reelección, y se negó a conformar la coalición presentándose únicamente como candidato de la UCR. Los resultados, con la victoria del candidato justicialista, significaron un fuerte golpe para el antialiancismo en la UCR y, paradójicamente, un fortalecimiento de la Alianza. 
autónomamente, enfrentar con éxito al peronismo en las elecciones presidenciales de octubre.

La creciente sensación de que derrotar al peronismo no será la fácil tarea que algunos preveían en los momento de euforia de fines de 1997 fortalece los compromisos aliancistas y otorga fuertes incentivos para un reparto parejo de los espacios de poder en disputa.

Los nuevos compromisos que enfrentará el FG, probablemente ocupando lugares importantes de gestión pública nacional y provincial, le demandarán el doble desafío de demostrar, por un lado, que puede gobernar progresista y eficazmente $y$, por el otro, que puede construir una estructura y una identidad partidaria de nuevo tipo capaz de sobrevivir frente a la fuerza histórica de su poderoso aliado.

Que el Frente Grande se transforme en un mero socio menor del radicalismo o que, por el contrario, sea capaz de institucionalizarse como una organización autónoma que represente los deseos de un amplio sector de la sociedad dependerá básicamente de la respuesta que sus dirigentes den a los mencionados problemas organizativos e identitarios.

\section{BIBLIOGRAFÍA}

AbAl Medina (h.), J. (1995): "La normalización del sistema partidario argentino", en J. Mayer y R. Sidicaro (Comp.): Política y sociedad en los años del menemismo, Carrera de Ciencia Política, EUDEBA, Universidad de Buenos Aires.

Abal Medina (h.), J. (1998a): "Reflexoes sobre a transformacao do sistema de partidos na argentina”, en $\mathrm{M}$. Baquero, A constracao de democracia na America Latina: estabilidade democratica, processos eleitorais, ciudadania e cultura política, Celes - Universidade Federal do Rio Grande do Sul, Brasil.

Abal Medina (h.), J. (1998b): "Los herederos del populismo: la experiencia del PRD y el Frente Grande", en Nueva Sociedad, número 156, Caracas.

Abal Medina (h.), J. y Castiglioni, F. (1999): “Crisis y transformación: los nuevos partidos políticos. El FG/ FREPASO y Forza Italia en perspectiva comparada", en Metapolítica, $\mathrm{n}^{\circ} 10$, volumen 3, abril-junio de 1999, México (En prensa).

ACUÑA, C. (1995): "Algunas notas sobre los juegos, las gallinas y la lógica política de los pactos constitucionales (Reflexiones a partir del pacto constitucional en la Argentina)", en C. Acuña, La nueva matríz política argentina, Buenos Aires: Nueva Visión.
Auyero, C. (1996): "La clave es una buena institucionalización”, en La Ciudad Futura, n 46 , primavera-verano, Buenos Aires.

Castiglioni, F., y Abal Medina (h.), J. (1997): "Nuevos partidos, mismos problemas: cambios y continuidades". Trabajo presentado en la mesa "Partidos Políticos y Sistemas Electorales", en el III Congreso Nacional de Ciencia Política, organizado por la Sociedad Argentina de Análisis Político y la Universidad Nacional de Mar del Plata, Mar del Plata, del 5 al 8 de noviembre de 1997.

Castiglioni, F. y ABAl Medina (h.), J. (1998): "Los nuevos partidos: partidos políticos y problemas de representación en Argentina", en Varios Autores: Partidos politicos y representación en América Latina, La Paz: Fundación F. Ebert, Ildis, Nueva Sociedad.

CAstiglioni, F. (1994): "Actores antipolíticos en la democracia" en VV.AA, I Congreso Peruano de Ciencia Política, Lima: Universidad de Lima.

CASTIGLIONI, F.(1995): "FREPASO: apuntes para el debate" en La Ciudad Futura, n. ${ }^{\circ} 45$

CAVArozzi, M. (1996): El capitalismo político tardío y su crisis en América Latina, Rosario: Homo Sapiens Ediciones.

CHERESKY, I. (1994): La innovación política. Reflexiones a partir de los resultados electorales del 10 de abril de 1994 en Argentina, Documentos de Trabajo, Instituto Gino Germani, Facultad de Ciencias Sociales, Universidad de Buenos Aires.

INGLEHART, R. (1990): Culture Shift, In Advanced Industrial Society, Princeton: Princeton University Press.

JANDA, K. (1993): "Comparative Political Parties: Research and Theory", en Finifer, A.: Political Science: The State of the Discipline II, Washington: American Political Science Association.

Manin, B. (1997): The Principles of Representative Government, Cambridge: Cambridge University Press.

Katz, R. y MAIR, P. (1997): "Party Organization, Party Democracy, and the Emergence of the Cartel Party", en P. Mair, Party System Change, Approaches and Interpretations, New York: Oxford University Press.

MocCA, E. (1994): "El tercero en discordia" en La Ciudad Futura, n. ${ }^{\circ} 40$.

MoccA, E. (1995): "La nueva oposición" en La Ciudad Futura, n. ${ }^{\circ} 43$.

Novaro, M. y Palermo, V. (1998): Los caminos del centroizquierda, Buenos Aires: Editorial Losada.

Panebianco, A. (1990): Modelos de partido, Madrid: Alianza Universidad.

Ware, A. (1996): Political Parties and Party Systems, New York: Oxford University Press. 


\section{RESUMEN}

El sistema argentino de partidos fue históricamente considerado como una forma especial de bipartidismo (polarizado, hegemónico, etcétera). Sin embargo en los últimos años el crecimiento de un nuevo partido, el Frente Grande, que se ubica en la centroizquierda del espectro y que está formado básicamente por antiguos militantes del Partido Justicialista, ha llevado al sistema hacia un formato pluripartidista limitado, abriendo una dinámica de coaliciones hasta entonces impensable. El trabajo aborda el surgimiento y crecimiento de este partido, analizando las similitudes y diferencias que presenta a la luz de las experiencias partidarias estudiadas tradicionalmente por la literatura especializada.

Palabras clave: partidos políticos, Argentina, Frente Grande, FREPASO, peronismo.

\section{ABSTRACT}

The Argentinean party system was historically considered as a special form of bipartidism (polarized, dominant, etc). However, in the last years the growth of a new party, the Frente Grande has driven to the political system towards a multi-party system and opening a new dynamic of coalitions unthinkable until then. The party stand in the center left of the spectrum and it's formed basically by old militants of the Peronist party. This work studies the source and growth of this party, analyzing the similarities and difference that it present under the light of the party experiences already studied by the traditional literature.

Key Words: Political Parties, Argentina, Frente Grande, FREPASO, Peronism.

\section{Desarrollo Económico Revista de Ciencias Sociales}

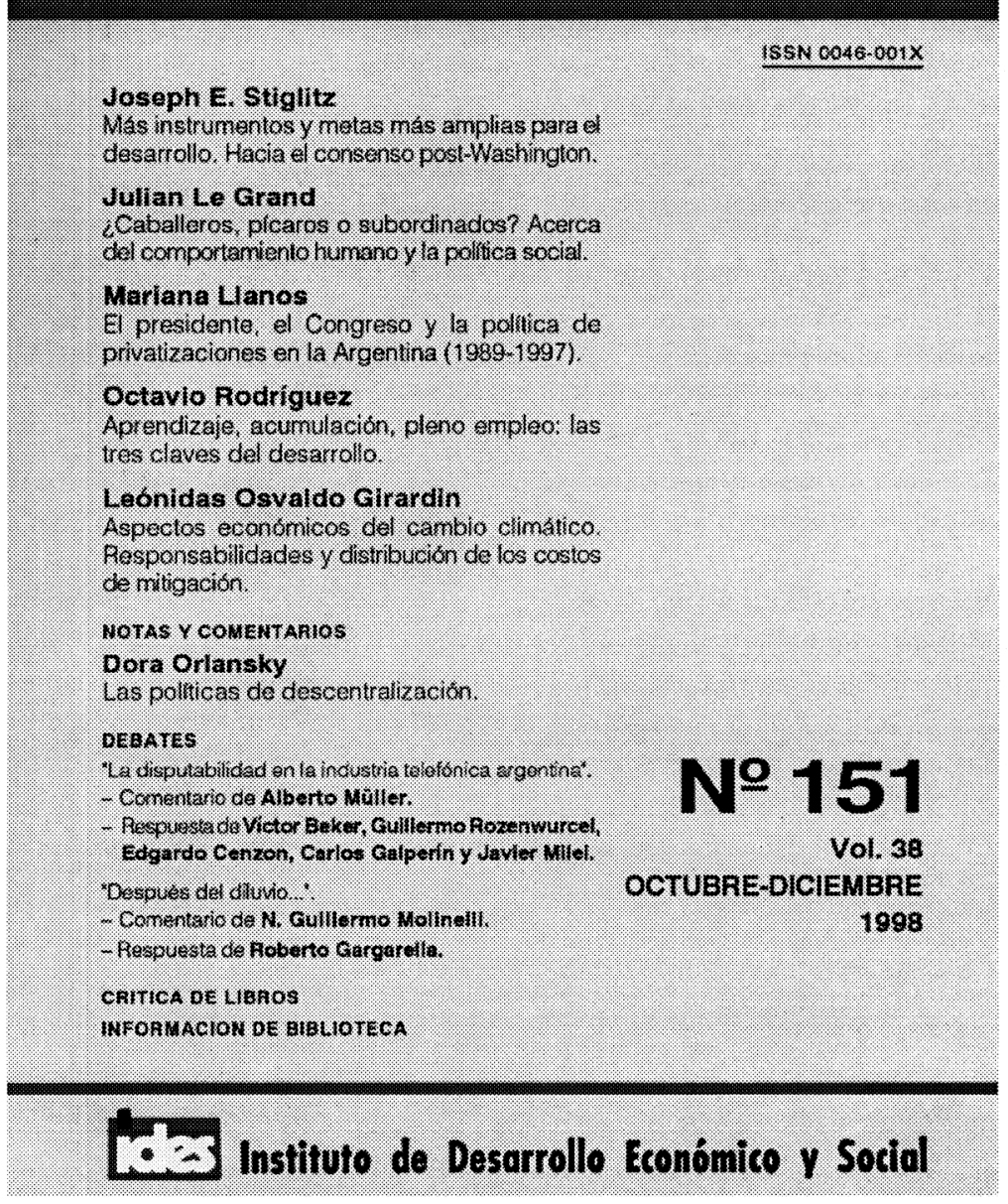

